\title{
The effects of associations and aging on illusory recollection
}

\author{
DAVID A. GALLO \\ Harvard University, Cambridge, Massachusetts \\ and \\ HENRY L. ROEDIGER III \\ Washington University, St. Louis, Missouri
}

\begin{abstract}
Younger and older adults (mean years $=20.5$ and 75 ) studied lists of associated words for a final recognition test. The length $(5,10$, or 15 associates) and modality (auditory or visual) of study lists were manipulated within subjects. For both groups, increasing the number of associates increased illusory recollections of a relatedlure's presentation (measured by source judgments and the Memory Characteristics Questionnaire). This pattern suggests that associative activation of the lure influenced illusory recollection, and aging spared this process. In contrast, age impaired the recollection of source for studied words (auditory or visual) and had identical effects on source attributions for related lures. This pattern suggests that the true recollection of source influenced illusory recollection of source, and age impaired this process. To account for these and other results, we propose that associative activation drives an attribution process that binds subjectively detailed features to a false memory.
\end{abstract}

One of the most intriguing phenomena of human memory is illusory recollection, or the subjectively detailed nature of some false memories. Roediger and McDermott (1995) and Read (1996) discovered some of the greatest levels of illusory recollection ever found on standard recognition and recall tests. After studying lists of associated words, subjects frequently claimed to "remember" details about the presentation of nonstudied associates (as opposed to claims of "knowing"; Tulving, 1985). Subsequent work using this task (often referred to as DRM, after Deese, 1959, and Roediger \& McDermott, 1995) revealed that subjects falsely recollect very specific details about the occurrence of these related lures in the study list. These recollections include the voice or modality in which the related lure was presented, its position in the list, neighboring words, and personal reactions to the word when it was presented (e.g., Gallo, McDermott, Percer, \& Roediger, 2001; Hicks \& Marsh, 1999; Mather, Henkel, \& Johnson, 1997; Neuschatz, Payne, Lampinen, \& Toglia, 2001; Norman \& Schacter, 1997; Payne, Elie, Blackwell, \& Neuschatz, 1996). These findings, coupled with the fact that false recall and recognition of the related lure are made with strong confidence (Read, 1996; Roediger \& McDermott, 1995), demonstrate the subjectively compelling nature of these types of false memories.

We thank Jane McConnell, Kristina Olson, and Dan Yang for valuable assistance in conducting the experiments. This research was supported by National Institute of Aging Grant AG17481. Correspondence may be sent to D. A. Gallo, Psychology Department, Harvard University, Cambridge, MA 02138 (e-mail: dgallo@wjh.harvard.edu).
In many experiments using this task, and in contrast to many other false memory tasks, illusory recollection occurs as frequently (or as strongly) as true recollection (for a review, see Lampinen, Neuschatz, \& Payne, 1998). True recollection is sometimes greater than illusory recollection (e.g., Mather et al., 1997; Norman \& Schacter, 1997), but even in these cases, illusory recollection for related lures is almost always greater than that for unrelated lures (hereafter, we reserve the term illusory recollection for these relatedness effects on subjective judgments). Significant illusory recollection is even found under the strictest testing conditions. Instructing subjects (at test) to strategically avoid false memories, or even forcing them to change their subjective judgments made on a previous test (in an effort to correct errors), has only small effects on various measures of illusory recollection (e.g., "remember" or voice judgments; see Gallo, Roediger, \& McDermott, 2001; Lampinen, Neuschatz, \& Payne, 1999; Neuschatz et al., 2001). The latter findings are particularly informative. They suggest that subjective reports of illusory recollection truly reflect the subjective or phenomenological products of retrieval, as opposed to biases or guessing strategies that warned subjects would be able to consciously modify or to avoid.

Although there are several theories to account for false recall and false recognition in this paradigm, the processes that cause the subjectively detailed recollections that often accompany these false memories (i.e., illusory recollections) are poorly understood. For instance, we have proposed an activation/monitoring theory of false recall and recognition (e.g., Roediger, Watson, McDermott, \& Gallo, 2001). Studying the list activates the nonpresented associ- 
ate, via spreading activation among preexisting memory representations (at study or test). This activated representation might make the related lure more likely to be generated on a recall test, or might make it more familiar on a recognition test. False recall and recognition occur when the source of this activation is incorrectly monitored (or edited) and attributed to actual presentation. Other explanations are that overlapping semantic features or "gist" are encoded from the lists (e.g., Arndt \& Hirshman, 1998; Brainerd, Wright, Reyna, \& Mojardin, 2001), and these representations make the related lure more familiar. The important point for our present purposes is that although all of these theories can explain false recall and false recognition of the related lure, none of them fully considers how these false memories become embellished with subjectively detailed illusory recollections.

An early explanation of these illusory recollections, at least for "remember" judgments, was that the subject consciously generated the nonpresented associates at study and subsequently recollected these thoughts at test (Roediger \& McDermott, 1995). More recent findings force one to reject this explanation as too simple. First, Seamon et al. (2002) found that the frequency of overt rehearsals of the related lure correlated with false recall but not with "remember" judgments on a recognition test (which often occurred in the absence of any related lure rehearsal). Assuming that thoughts of the related lure would have been overtly verbalized, these data indicate that conscious generation of the lure at study is not necessary for subsequent illusory recollection. Second, internally generated thoughts of nonpresented associates, on their own, should not be accompanied with the detailed recollections of actual presentation that are typically observed (e.g., perceptual characteristics). Thinking of the related lure during study might make it more likely to be generated on a recall test (e.g., Smith, Gerkens, Pierce, \& Choi, 2002), but more theoretical development is needed in order to explain the detailed subjective judgments that often accompany these false memories.

\section{Associations and Illusory Recollection}

Gallo, McDermott, et al. (2001) discussed attribution processes as one potential explanation for the illusory recollection of study modality that we observed. In that study, half of the lists were presented auditorily, and half were presented visually. On a final recognition test, subjects often judged both list words and related lures as having been presented in the modality of the corresponding list. We proposed that, at test, the subjects recollected the modality of the corresponding list and attributed the lure to that modality. Such an attribution might occur explicitly, in the form of a strategic inference (i.e., "I think this word was presented in that list, and because that list was presented visually, this word must have been visually presented"). However, the aforementioned warning studies indicate that these source attributions are difficult to overcome, so they also might occur more automatically. The finding that subjects falsely remember details that cannot be associated with a source, such as personal reactions, also suggests that such source-based inferences cannot be the entire explanation of illusory recollection.

It has been argued that when an item is fluently processed (e.g., more easily read on a recognition test), this fluent processing can be nonconsciously attributed to a plausible source (see Jacoby, Kelley, \& Dywan, 1989; Whittlesea, 2002). Gallo, McDermott, et al. (2001) proposed that this type of automatic attribution might explain the subjective experience of illusory recollection in DRM. For instance, to make a modality decision, our subjects might have recollected the modality of the list and imagined the related lure as occurring in that modality. This imagination could be mistaken for true recollection due to a fluency-based attribution. Because the related lure is highly associated to the study list, associative activation might enhance the processing fluency of the lure, thereby triggering an attribution process.

In the present study, we manipulated associative activation by varying the number of associates studied for each related lure. Presenting more associates should increase associative activation of the lure. In agreement with this claim, longer lists have been shown to yield greater false recognition in this paradigm (e.g., Arndt \& Hirshman, 1998; Robinson \& Roediger, 1997). It is unknown whether increasing list length also will affect illusory recollection, but it should if associative activation drives an attribution process that causes illusory recollection.

To test this prediction, we used two methods to measure recollection. First, subjects made a source judgment by indicating which modality had been used to present a word (lists were presented either auditorily or visually). An "unsure" option was also included, so that subjects were not forced to make a source decision. Second, after each modality judgment, subjects rated their memories for each word along four dimensions (perceptual details, emotional reactions, associations, and trying to remember), using the Memory Characteristics Questionnaire (MCQ; Johnson, Foley, Suengas, \& Raye, 1988). According to an activationbased attribution theory, increasing the list length (and hence associative activation) should increase the likelihood of illusory recollection, measured with either method.

\section{Aging and Illusory Recollection}

To further investigate the mechanisms of illusory recollection, we compared younger and older adults. In some studies, older adults have shown greater false recognition than younger adults have shown (e.g., Norman \& Schacter, 1997; Schacter, Israel, \& Racine, 1999). One explanation for this difference is that automatic associative processes are spared with age, but that monitoring processes are sometimes impaired by frontal cortex dysfunction (e.g., Balota et al., 1999). The idea is that related lures are just as likely to seem familiar for older adults (due to activation), and that this familiarity is less likely to be edited (or "monitored") with age. As a result, older adults are more likely to make familiarity-based errors than younger adults are (e.g., Tun, Wingfield, Rosen, \& 
Blanchard, 1998; cf. Jacoby, 1999). However, it is important to note that age differences in absolute levels of false recognition are not always obtained in the DRM paradigm, at least under standard conditions (see, e.g., Benjamin, 2001; Budson, Daffner, Desikan, \& Schacter, 2000; Intons-Peterson, Rocchi, West, McLellan, \& Hackney, 1999 ; Kensinger \& Schacter, 1999). This outcome may indicate that monitoring processes are not necessarily impaired with aging, or that, under standard DRM conditions, having additional monitoring resources available does not necessarily help younger adults reduce false recognition.

This cognitive profile of aging allows specific predictions with respect to illusory recollection. First consider the influence of age on overall levels of illusory recollection. If illusory recollection is driven by a relatively automatic attribution process, one might expect it to be intact in older adults. Subjective reports of illusory recollection would therefore be equivalent or greater in older adults, depending on whether or not monitoring processes are impaired (see Norman \& Schacter, 1997). These predictions should hold for illusory recollections measured by either source judgments or the MCQ. However, illusory recollection of modality might also be influenced by true recollection of source. To determine the modality of a related lure, subjects might try to recollect the modality of the corresponding list. In this case, one would expect ageassociated deficits in source memory (e.g., Glisky, Rubin, $\&$ Davidson, 2001) to cause illusory recollection of source to be "less accurate," or less likely to be congruent with the modality of the corresponding list.

Next consider the influence of list length on illusory recollection in older adults. If associative activation is intact with aging (Balota et al., 1999), then increasing the number of studied associates should increase associative activation in older adults, just as in younger adults. If illusory recollection is driven by associative activation, then increasing list length should increase illusory recollection in both age groups. This prediction should hold for illusory recollection measured by either source judgments or MCQ ratings.

\section{METHOD}

\section{Subjects}

One hundred eight subjects participated for course credit or $\$ 10$. Half were Washington University undergraduates (mean age $=20.5$ years, $S D=3.5 ; 31$ females), and half were older adults recruited from the Washington University subject pool $(M=75, S D=4.1 ; 36$ females). The older adults had completed an average of 14.5 years $(S D=2.5)$ of formal education, comparable to that of the younger adults $(M=14.1, S D=1.5)$.

\section{Materials and Design}

The study materials were 27 DRM lists that had elicited high levels of false recognition in the Stadler, Roediger, and McDermott (1999) norms. The lists were divided into 3 sets of 9 that were matched on their mean probability of false recognition (.71). The lists within each set were then clustered into threes, again matching for false recognition. The lists were blocked at study, and the words within each list were arranged by decreasing associative strength. As in Robinson and Roediger (1997), shorter list lengths were achieved by removing words from the end of the list.

Study modality was manipulated within subjects. The subjects studied nine auditory lists and nine visual lists. Words corresponding to the nine nonstudied lists were used as lures on the recognition test. The lists were rotated through the auditory, visual, and nonstudied conditions an equal number of times across counterbalancing conditions. The lists were blocked by study modality, and the order of the blocks was counterbalanced between subjects. List length was also manipulated within subjects. Within each modality, three lists were presented at each of the three lengths $(5,10$, and 15 words). The lists were rotated through the length conditions an equal number of times across counterbalancing conditions. One list of each length was presented in the beginning, middle, and end of each modality block, but the order was remixed every three lists so that subjects could not anticipate the length of an upcoming list.

All subjects received the same final recognition test. Each of the 27 lists contributed 5 words to the test: list words from Serial Positions $1,3,5$, and 10 , and the nonstudied related lure. Note that the word from Serial Position 10 was a lure for 5-word study lists. The resulting test contained 135 words (66 targets and 69 lures). Test words were randomly arranged, with the constraint that words corresponding to the same list were separated by at least 2 other words.

\section{Procedure}

The subjects were informed that they would see and hear several word lists of varying lengths. They were instructed to pay careful attention to each word, because their memory would later be tested (the nature of the test was unspecified at study). The presentation parameters were closely modeled after those of Gallo, McDermott, et al. (2001, Experiment 2). Each word from the visual lists was presented on the computer screen for $500 \mathrm{msec}$, with successive words separated by a $500-\mathrm{msec}$ blank screen. The words were printed in lowercase letters at the center of the computer screen (24-point BigFont). The auditory lists were presented over headphones in a male voice, with $500 \mathrm{msec}$ of silence spliced between successive words. The lists were separated by a 2 -sec "next list" prompt, and a visual prompt indicated the modality of the upcoming block of lists. The test items were visually presented using the same format as that for the visually presented studied items.

Each test word was preceded with a test number that corresponded to the number on the subject's test sheet. For each word, the subjects first made an old/new recognition decision by circling the appropriate response. After each old decision, they made a source judgment by circling "auditory," "visual," or "unsure." They then rated their memory for that word along four separate dimensions, using a modified version of the MCQ. These included perceptual details (vividness of recollections of study presentation), emotional reactions (degree of emotional response at study), associations (how much the word was associated to other words or concepts at study), and trying to remember (how much the subject tried to memorize or rehearse the word at study). The subjects rated their memory for each of these dimensions using a 1-5 rating scale (low-high), and it was stressed that these ratings were different from confidence ratings. This questionnaire was closely modeled after that used by Mather et al. (1997), and we thank Mara Mather for supplying their instructions.

\section{RESULTS}

\section{Old/New Judgments}

Data from the old/new judgments are summarized in Table 1 (false alarms to control items from nonstudied lists, or unrelated lures, are in the note). In all conditions, recognition of list words (collapsing across Serial Positions 1, 
Table 1

Mean Proportion of Words Recognized as Old

\begin{tabular}{|c|c|c|c|c|c|c|}
\hline \multirow[b]{2}{*}{ List Length } & \multicolumn{3}{|c|}{ Younger Adults } & \multicolumn{3}{|c|}{ Older Adults } \\
\hline & Aud. & Vis. & $M$ & Aud. & Vis. & $M$ \\
\hline \multicolumn{7}{|c|}{ List Words } \\
\hline 5 words & .66 & .66 & .66 & .55 & .55 & .55 \\
\hline 10 words & .65 & .68 & .66 & .60 & .56 & .58 \\
\hline 15 words & .65 & .68 & .66 & .60 & .63 & .62 \\
\hline$M$ & .65 & .67 & .66 & .58 & .58 & .58 \\
\hline Adjusted & .42 & .43 & .42 & .35 & .35 & .35 \\
\hline \multicolumn{7}{|c|}{ Related Lures } \\
\hline 5 words & .60 & .59 & .60 & .55 & .48 & .51 \\
\hline 10 words & .68 & .64 & .66 & .66 & .64 & .65 \\
\hline 15 words & .78 & .67 & .73 & .73 & .71 & .72 \\
\hline$M$ & .69 & .63 & .66 & .65 & .61 & .63 \\
\hline Adjusted & .37 & .32 & .35 & .33 & .29 & .31 \\
\hline
\end{tabular}

Note-Aud. = Auditory study list, Vis. = visual study list. For both groups, the false alarm rate from nonstudied lists (baserate false alarms) was .24 for list word controls and .31 for related lure controls. For each subject, means were adjusted by subtracting their baserate false alarms (see text). Fifty-four subjects contributed to each age group.

3 , and 5) and false recognition of related lures was significantly greater than false recognition of the corresponding unrelated lures (all $\mathrm{ps}<.01$ ). This pattern demonstrates reliable true and false memory effects. Absolute levels of false recognition were constant over age, but true recognition was impaired with age (consistent with comparable conditions in Budson et al., 2000; Kensinger \& Schacter, 1999). Finally, false recognition was greater with longer lists and with auditory lists.

We analyzed the old/new data for list words and related lures both before and after the baserate false alarms were subtracted (i.e., false alarms to unrelated lures). These baserate false alarms were greater for the related lure controls (.31) than for the list word controls (.24) $[t(107)=$ $5.21, S E M=.015, p<.01]$, as is often observed with these materials (e.g., Roediger \& McDermott, 1995; Schacter, Verfaellie, \& Pradere, 1996; Seamon, Luo, \& Gallo, 1998). However, the baserate means were identical across age groups. Because both length and modality were manipulated within subjects (and hence corresponded to the same baserates), all statistical analyses involving these two variables yielded equivalent results for both adjusted and unadjusted data. We report only the analyses from data that were adjusted for baserate false alarms by subtraction. For list words, this difference reflects the effect of studying the word on subsequent recognition (i.e., "true recognition"). For related lures, it reflects the effect of studying a related list of words on subsequent false alarms (i.e., the relatedness effect on false recognition, or simply "false recognition"). All statistical results reported in this article were significant at the conventional level of significance $(p<.05)$, unless otherwise noted.

A 3 (list length) $\times 2$ (modality) $\times 2$ (age) analysis of variance (ANOVA) on false recognition confirmed that there was an effect of length $\left[F(2,212)=24.74, M S_{\mathrm{e}}=\right.$ $0.062]$ and an effect of modality $\left[F(1,106)=5.11, M S_{\mathrm{e}}=\right.$
$0.065]$. There was no effect of age $(F<1)$, and there were no significant interactions. The modality effect (auditory $>$ visual) replicates prior findings, at least for younger adults with visual tests (Gallo, McDermott, et al., 2001, Smith \& Hunt, 1998), and extends them to older adults. ${ }^{1}$ More important for the present purposes is the effect of list length in both groups, which reflects the increase from .24 to .34 to .41 (for 5-, 10-, and 15-word lists). A similar ANOVA on true recognition revealed a main effect of age $[F(1,106)=$ $4.79, M S_{\mathrm{e}}=0.203$ ], confirming that true recognition was greater for the younger adults (.42) than for the older adults (.35). No other effects or interactions were significant. Overall, these length effects are consistent with prior work in younger adults, which has demonstrated that list length affects false recognition more than it affects true recognition (if at all) in this paradigm (e.g., Arndt \& Hirshman, 1998; Robinson \& Roediger, 1997). It also extends these list length effects to older adults.

\section{Source Judgments}

The results of the source judgments are summarized in Table 2. Preliminary analyses (with data pooled across list length) revealed that study modality did not have any main effects or interactions on these judgments, so the data were pooled across modality. Judgments that corresponded to the modality of the relevant list were considered "congruent" and those that corresponded to the other modality were considered "incongruent" (e.g., an "auditory" judgment for a related lure whose related list was presented auditorily was considered congruent). For each subject, the probability of making each judgment (congruent, incongruent, or unsure) was then divided by their probability of saying "old" to each item type, so that in any condition these three proportions sum to one. This calculation was done so that differences in source judgments would be independent from differences in overall levels of old/new 
Table 2

Mean Proportion of Recognized Words Given Congruent, Incongruent, or Unsure Source Judgments

\begin{tabular}{|c|c|c|c|c|c|c|}
\hline \multirow[b]{2}{*}{ List Length } & \multicolumn{3}{|c|}{ Younger Adults } & \multicolumn{3}{|c|}{ Older Adults } \\
\hline & Cong. & Incg. & Unsure & Cong. & Incg. & Unsure \\
\hline \multicolumn{7}{|c|}{ List Words } \\
\hline 5 words & .64 & .17 & .18 & .47 & .34 & .18 \\
\hline 10 words & .68 & .15 & .17 & .53 & .29 & .18 \\
\hline 15 words & .70 & .16 & .13 & .50 & .31 & .18 \\
\hline$M$ & .67 & .16 & .16 & .50 & .31 & .18 \\
\hline \multicolumn{7}{|c|}{ Related Lures } \\
\hline 5 words & .60 & .20 & .20 & .48 & .32 & .19 \\
\hline 10 words & .66 & .12 & .22 & .53 & .26 & .20 \\
\hline 15 words & .73 & .10 & .17 & .52 & .28 & .19 \\
\hline$M$ & .66 & .14 & .20 & .51 & .29 & .20 \\
\hline
\end{tabular}

Note-Judgments are expressed as proportions of the hit rate or false alarm rate, and sum to 1 . In younger adults, the proportions of "auditory," "visual," and "unsure" judgments were $.30, .31$, and .39 for list word controls, and $.28, .24$, and .48 for related lure controls. The same proportions in older adults were $.35, .34$, and .29 for list words, and $.33, .30$, and .35 for related lures. Fifty subjects contributed to the younger group, and 52 contributed to the older group.

recognition. A few subjects did not respond "old" to any of the six related lures in a given length condition, so subsequent subjective judgments were not obtained. Data from these subjects (4 younger adults and 2 older adults) were excluded, resulting in 50 younger adults and 52 older adults in the analysis. Modality attributions to unrelated lures (i.e., control lures) could not be assigned as congruent or incongruent, so these are listed in the note to Table 2.

In all conditions, the subjects were less likely to give "unsure" judgments to related lures than to control lures from nonstudied lists (all $p$ s $<.05$ ). Thus, even when both types of lures were falsely recognized, the subjects were more likely to give a source judgment to related lures than to unrelated lures. In the younger adults, both list words and related lures were most likely to be assigned to the modality of their corresponding list, whereas unrelated lures were most likely to be given an "unsure" judgment (replicating Gallo, McDermott, et al., 2001). ${ }^{2}$ The older adults showed a similar pattern, but the effects were weaker, and the ratings for unrelated lures were more evenly distributed across the three response categories. As expected, memory for the source of studied items was impaired in the older adults, and, more telling, source judgments for related lures followed the same pattern. Finally, and most important, increasing list length increased congruent attributions to both the related lures and the list words.

We restricted the following analyses to "congruent" judgments, pooled across study modality. Because lures from nonstudied lists could not be binned according to congruency, the data in these analyses were not adjusted for these baserates (via subtraction). However, as with the old/new data, the same baserate false alarms corresponded to list items and related lures across the length conditions, so adjusting for baserates would not have affected the overall pattern of length effects reported here. Further, modality attributions for unrelated lures (collapsing across "auditory" and "visual" attributions) were numer- ically greater for older adults (.35 for list words and .32 for related lures) than for younger adults (.31 and .26). Because the age effects on congruent judgments were always in the opposite direction (young > old), taking baserate differences into account would have only augmented these age effects.

A 2 (age) $\times 3$ (length) ANOVA on congruent judgments for related lures revealed a main effect of length $\left[F(2,200)=3.18, M S_{\mathrm{e}}=0.054\right]$. This finding indicates that increasing list length increased illusory recollection of source (mean $=.54$ to .60 to .62 ). There was also a main effect of age $\left[F(1,100)=13.35, M S_{\mathrm{e}}=.135\right]$, and no interaction. Younger adults were more likely to make congruent attributions (.66) than were older adults (.51). A similar analysis for list words also revealed a main effect of length $\left[F(2,200)=4.00, M S_{\mathrm{e}}=0.021\right]$, a main effect of age $\left[F(1,100)=30.84, M S_{\mathrm{e}}=0.076\right]$, and no interaction. Again, increasing length increased the likelihood of making congruent attributions (mean $=.55, .60$, and .60 ), and younger adults were more likely to make congruent attributions (.67) than were older adults (.50).

Although the older adults made fewer congruent attributions than did the younger adults, they were overall just as likely to make source attributions as were younger adults (as opposed to "unsure" judgments). For related lures, the sum of congruent and incongruent attributions was .80 for both groups. For list words, total attributions were .81 for older adults and .83 for younger adults. These data indicate that, despite age differences in the quality of these attributions, the groups were equally compelled to attribute a modality to related lures and list words.

\section{MCQ Ratings}

The ratings for perceptual details and emotional reactions are summarized in Table 3. For words that were not actually presented, these ratings indicate levels of illusory recollection, so we were particularly interested in these 
Table 3

Mean MCQ Ratings (1-5) for Recollections of Perceptual Details and Emotional Reactions

\begin{tabular}{lccccc}
\hline & \multicolumn{2}{c}{ Perceptual Details } & & \multicolumn{2}{c}{ Emotional Reactions } \\
\cline { 2 - 3 } \cline { 5 - 6 } List Length & Younger & Older & & Younger & Older \\
\hline & \multicolumn{4}{c}{ List Words } \\
5 words & 2.79 & 2.41 & & 2.69 & 2.53 \\
10 words & 2.76 & 2.51 & 2.74 & 2.56 \\
15 words & 2.76 & 2.48 & 2.71 & 2.54 \\
$M$ & 2.77 & 2.47 & 2.71 & 2.54 \\
Baseline & 1.92 & 2.14 & 2.00 & 2.08 \\
Adjusted & .85 & .33 & .71 & .47 \\
& & Related Lures & & \\
5 words & 2.57 & 2.41 & 2.48 & 2.41 \\
10 words & 2.43 & 2.48 & 2.48 & 2.69 \\
15 words & 2.68 & 2.59 & 2.65 & 2.59 \\
$M$ & 2.56 & 2.49 & 2.54 & 2.56 \\
Baseline & 1.96 & 2.12 & 2.02 & 2.22 \\
Adjusted & .60 & .37 & .52 & .35 \\
\hline
\end{tabular}

Note-Ratings are pooled across study modality. Higher ratings indicate greater memory for that characteristic. Baselines represent ratings to control items from nonstudied lists. Forty-five subjects contributed to the younger group, and 44 contributed to the older group.

ratings. The ratings for associations and trying to remember are summarized in Table 4. These ratings also refer to processes that occurred during the study phase, but they did not necessarily require remembering the actual presentation of the word in the list. A subject might remember thinking about a word when another associate had been presented (an association), or might remember covertly rehearsing a word after the list had been presented (trying to remember). Thus, these judgments do not necessarily refer to illusory recollection per se.

As with the source judgments, preliminary analyses revealed that there were no main effects or interactions involving study modality on any of the MCQ ratings. The data were therefore pooled across modalities. In all but two instances, list words and related lures were given significantly greater ratings than were unrelated lures (baseline ratings), demonstrating true and illusory recollection of these characteristics $(p s<.05)$. (The two nonsignificant differences were for the older adults' ratings of emotional reactions and trying to remember for related lures in the 5-word condition.) The MCQ ratings for list words tended to be impaired in the older adults, whereas the ratings for related lures tended to be the same across age groups. Most important, increasing list length increased the ratings given to related lures, but did not affect the ratings given to list words.

Data from the 4 younger and 2 older subjects who did not falsely recognize any related lures in a given length condition were again excluded from analysis. In addition, some subjects never false alarmed to related lures from nonstudied lists (4 younger and 6 older), list words from nonstudied lists ( 1 older), or both (1 from each group). Because these data were necessary for calculating adjusted MCQ scores (again via subtraction), these subjects were also excluded in the analyses to be reported, yielding 45 younger adults and 44 older adults. All of the following analyses were conducted on adjusted MCQ scores. Unless otherwise noted, identical effects of length were obtained by analyzing the unadjusted data, before these additional subjects were excluded.

For the perceptual details rating, a 2 (age) $\times 3$ (length) ANOVA on related lures revealed a significant effect of length $\left[F(2,174)=3.44, M S_{\mathrm{e}}=0.244\right]$. Illusory recollection of details generally increased as list length increased (mean $=.45, .41$, and .60). There was no effect of age and no interaction. For list words, there was a significant effect of age $\left[F(1,87)=21.73, M S_{\mathrm{e}}=0.859\right]$, and no effect of length or interaction. The younger adults remembered more details for true memories (.85) than did the older adults (.33). Similar analysis of emotional reactions revealed a marginal effect of length for related lures $[F(2,174)=3.04$, $\left.M S_{\mathrm{e}}=0.245, p=.05\right]$ (means $=.33$ to .47 to .50$)$. There was no effect of age and no interaction. Analysis of list words revealed a marginal effect of age [younger $>$ older; $\left.F(1,87)=3.29, M S_{\mathrm{e}}=1.22, p=.07\right]$, and no effect of length or interaction.

Turn next to the data in Table 4. Analysis of associations ratings for related lures yielded a marginal effect of length $\left[F(2,174)=2.70, M S_{\mathrm{e}}=0.373, p=.07\right]$. (This effect was significant on analysis of the raw data.) Again, these ratings increased with longer lists (from .69 to .75 to .89 ). The effect of age (younger $>$ older) was significant $\left[F(1,87)=6.19, M S_{\mathrm{e}}=2.32\right]$, and there was no interaction. For the list words, there was a significant effect of age [younger $>$ older; $F(1,87)=15.26, M S_{\mathrm{e}}=1.73$ ], and no effect of length or interaction. Similar analyses were conducted on the trying to remember ratings ( 2 older adults and 1 younger adult failed to give a rating for some list words or related lures, so their data were excluded). For

Table 4

Mean MCQ Ratings (1-5) for Recollections of Associations and Trying to Remember

\begin{tabular}{lccccc}
\hline & \multicolumn{2}{c}{ Associations } & & \multicolumn{2}{c}{ Trying to Remember } \\
\cline { 2 - 3 } \cline { 5 - 6 } List Length & Younger & Older & & Younger & Older \\
\hline & & List Words & & \\
5 words & 3.30 & 2.84 & 2.55 & 2.51 \\
10 words & 3.30 & 2.95 & 2.44 & 2.52 \\
15 words & 3.35 & 2.93 & 2.59 & 2.56 \\
$M$ & 3.32 & 2.91 & 2.52 & 2.53 \\
Baseline & 2.21 & 2.43 & 1.83 & 2.31 \\
Adjusted & 1.10 & .48 & .69 & .22 \\
& & Related Lures & & \\
5 words & 3.16 & 2.88 & 2.36 & 2.50 \\
10 words & 3.11 & 3.05 & 2.32 & 2.70 \\
15 words & 3.36 & 3.09 & 2.43 & 2.59 \\
$M$ & 3.21 & 3.01 & 2.37 & 2.60 \\
Baseline & 2.21 & 2.47 & 1.84 & 2.37 \\
Adjusted & 1.00 & .54 & .53 & .23 \\
\hline
\end{tabular}

Note-Ratings are pooled across study modality. Higher ratings indicate greater memory for that characteristic. Baselines represent ratings to control items from nonstudied lists. Forty-five subjects contributed to the younger group, and 44 contributed to the older group. 
the related lures, there was no effect of age or length and no interaction. For list words, the effect of age (younger $>$ older) was significant $\left[F(1,85)=7.87, M S_{\mathrm{e}}=1.90\right]$. There was no effect of length, and no interaction.

Norman and Schacter (1997) found that younger adults were more likely than older adults to discriminate between list words and related lures when using a rating of perceptual details. Considering only the unadjusted ratings in our study (as in Norman \& Schacter, 1997), the ratings for list words were significantly greater than those to related lures on all of the dimensions except associations for the younger adults (collapsing across length, all $p$ s $<.05$ ). None of these differences were significant in the older adults; if anything, the means were consistently in the opposite direction. By this index, illusory recollection was more compelling in older adults than in younger adults, but this difference was primarily caused by age deficits in true recollection, so it is not as relevant as is a direct comparison of the absolute levels of illusory recollection across age groups. When we compared levels of adjusted ratings made to related lures across groups (i.e., the relatedness effect), the older and younger adults showed equivalent levels of illusory recollection. Thus, there was little evidence that age modulated the relatedness effect on illusory recollection, as was the case with false recognition and overall levels of modality attributions (congruent + incongruent).

\section{DISCUSSION}

In younger adults, increasing list length increased illusory recollections of source and of various item-specific characteristics measured by the MCQ. These findings suggest that increasing associative activation (via list length) enhanced the attribution process that drives illusory recollection. Similar length effects were found in older adults, indicating that this attribution process is intact in aging. Interestingly, congruent source judgments for list items also were affected by list length. We did not predict this effect, but in hindsight, if subjects recollected the modality of a list to make source attributions for related lures, then it makes sense that this associatively based attribution process would operate on list items, too. MCQ judgments could not be based on such source attributions, and these ratings for list items were not affected by length. The other main finding was that, in older adults, source judgments for list items and related lures were less likely to match the modality of the corresponding list. Age impaired the ability to recollect the modality of the corresponding study list, and this affected source attributions for both studied items and related lures.

Two other recent findings are relevant to the present results. Gallo and Roediger (2002) manipulated the degree of associative strength between the list words and the related lure (i.e., backward associative strength). Replicating prior results, we found that lists with greater associative strength were more likely to elicit false recall and false recognition. More important, we found that associative strength was positively related to the degree of illusory recollection that accompanied false recognition (measured with "remember" judgments and confidence ratings). Illusory recollection was more likely to occur after studying lists of stronger associates. Taking a different approach, Hicks and Hancock (2002) capitalized on the variability of associative strength within each list. DRM lists were presented by two voices, with one voice reading the words that were more strongly associated to the related lure. On a subsequent voice-attribution test, subjects were more likely to judge the related lure as having occurred in the voice that presented the stronger associates. Thus, even at a given level of associative activation, illusory recollection was more likely to take on characteristics of the stronger associates.

Collectively, these results suggest that an associatively driven attribution process causes illusory recollection in the DRM paradigm. This process is thought to be akin to the attribution processes proposed by Jacoby and others, although in those accounts the attribution process is typically thought to cause familiarity, as opposed to detailed recollections (e.g., Jacoby et al., 1989; Leboe \& Whittlesea, 2002; Lindsay \& Kelley, 1996). To explain how subjectively detailed features get bound to the false memory, additional processes are necessary. For instance, in response to test queries about the phenomenological experience of remembering, subjects may imagine features of the related lure's presentation in an effort to try to remember. Because associative activation makes the processing of the related lure more fluent, these imagined features may be mistakenly attributed to true memories.

Although our effects of list length indicate a role for associative activation in the attribution process (as do the results of Gallo \& Roediger, 2002, and Hicks \& Hancock, 2002), our additional claim that imagination provides the subjective content of the illusory recollection is only speculative. An alternative mechanism, involving "feature borrowing," also deserves consideration (see Lampinen et al., 1999; Reyna \& Titcomb, 1996; and Schacter, Norman, \& Koutstaal, 1998, for related ideas). Under this account, stored features that correspond to list words become bound to the related lure because of preexisting associative connections. Rather than imagine the features that correspond to illusory recollection, these features are partially recollected from true memories and attributed to the false memory. More work to investigate these two possibilities is needed (see McKone \& Murphy, 2000, for relevant findings and discussion).

It is important to note that associative activation may not be the only process that contributes to fluent processing of the lure, thereby triggering the attribution process. Similarity-based mechanisms, such as those proposed by fuzzy trace theory (Brainerd et al., 2001) or global-matching models (Arndt \& Hirshman, 1998), might also play a role. Although there are important differences between these last two models, they both focus on feature-overlap between the related lure and the list words, as opposed to activation among preexisting associations. Such models have traditionally explained false recognition in terms of fa- 
miliarity - lures that have a strong similarity to the list will seem more familiar than unrelated lures-but they could be expanded to account for illusory recollection. Indeed, more recent extensions of fuzzy trace theory have introduced a parameter called "phantom recollection" to mathematically model illusory recollection (Brainerd et al., 2001; see also Reyna \& Titcomb, 1996). To explain the effects of list length, such a similarity-based account could assume that increasing the number of studied associates increases the number of features stored in memory that are similar to those of the related lure (or the encoding of the "gist" of a list, in terms of fuzzy trace theory). As a result, the lure would be more fluently processed at test, thereby increasing illusory attributions.

Elsewhere we have argued that both associative activation and similarity-based mechanisms make unique contribution to DRM false recognition (Gallo \& Roediger, 2002). Here, we argue that associative mechanisms play a role in causing illusory recollection beyond any potential role of similarity-based processes. This conclusion is bolstered by comparisons with other false memory paradigms that use different types of related materials. First, false recognition following orthographically related words (e.g., studying fate and fake to elicit false recognition of fade) elicits more "know" than "remember" responses (Schacter, Verfaellie, \& Anes, 1997; Watson, Balota, \& Roediger, 2003). Second, when several pictures are presented to elicit false recognition of a novel but similar picture, false recognition is made with low confidence in younger adults (e.g., Koutstaal \& Schacter, 1997), in contrast with the high-confidence false alarms typically found in the DRM procedure. Finally, category-based false recognition (e.g., falsely remembering robin when other birds have been studied) can elicit more "know" or "guess" responses as opposed to "remember" responses (e.g., Dewhurst, 2001; Seamon, Luo, Schlegel, Greene, \& Goldenberg, 2000), and these "remember" responses are rarely as high as those in the DRM task (see also Brainerd et al., 2001).

In all of these cases-phonological associates, similar pictures, and categorized lists - the related lure is chosen because it is highly similar to items in the list. If only similarity-based mechanisms were involved, then these lists should elicit levels of illusory recollection as high as DRM lists, but typically they do not. Instead, the presentation of associates that converge on the related lure (as in the present study) appears to play a key role in eliciting illusory recollection. Similarity-based models could finesse this point by considering associations as the penultimate index of similarity, but to us this undermines a useful distinction between similarity and association. Although semantically similar words tend to be associated (hot-warm), associated words do not have to be similar (cradle-baby), just as nonlaboratory events can be associated despite not being similar (e.g., reading articles and drinking coffee). This is not to say that similarity-based processes play no role in illusory recollection, only that associative processes appear to make a unique contribution.
In conclusion, we note that increased false memory (false recognition and illusory recollection) is not an inevitable consequence of aging. Younger and older adults were equally likely to falsely recognize related lures, to attribute them to a source (collapsing across congruency), and to rate them on item-specific characteristics corresponding to actual presentation (details and reactions). This pattern suggests that activation and monitoring were spared in our sample of older adults, or that our younger adults did not take advantage of additional monitoring resources to differentially reduce false memories. The fact that we found age differences (younger $>$ older) in true recognition, in the true recollection of source, and on itemspecific characteristics of true memories suggests that younger adults might have had additional monitoring resources available to them. However, exactly how true recollection and source memory could reduce talse recognition under typical DEM conditions is not fully understood.

\section{REFERENCES}

Arndt, J., \& Hirshman, E. (1998). True and false recognition in MINERVA2: Explanations from a global matching perspective. Journal of Memory \& Language, 39, 371-391.

Balota, D. A., Cortese, M. J., Ducher, J. M., Adams, D., Roediger, H. L., III, McDermott, K. B., \& Yerys, B. E. (1999). Veridical and false memories in healthy older adults and in dementia of the Alzheimer's Type. Cognitive Neuropsychology, 16, 361-384.

Benjamin, A. S. (2001). On the dual effects of repetition on false recognition. Journal of Experimental Psychology: Learning, Memory, \& Cognition, 27, 941-947.

Brainerd, C. J., Wright, R., Reyna, V. F., \& Mojardin, A. H. (2001). Conjoint recognition and phantom recollection. Journal of Experimental Psychology: Learning, Memory, \& Cognition, 27, 307-327.

Budson, A. E., Daffner, K. R., Desikan, R., \& Schacter, D. L. (2000). When false recognition is unopposed by true recognition: Gist-based memory distortion in Alzheimer's disease. Neuropsychology, 14, 277-287.

DEESE, J. (1959). On the prediction of occurrence of particular verbal intrusions in immediate recall. Journal of Experimental Psychology, 58, $17-22$.

Dewhurst, S. A. (2001). Category repetition and false recognition: Effects of instance frequency and category size. Journal of Memory \& Language, 44, 153-167.

Gallo, D. A., McDermott, K. B., Percer, J. M., \& Roediger, H. L., III (2001). Modality effects in false recall and false recognition. Journal of Experimental Psychology: Learning, Memory, \& Cognition, 27, 339-353.

Gallo, D. A., \& Roediger, H. L., III (2002). Variability among word lists in eliciting memory illusions: Evidence for associative activation and monitoring. Journal of Memory \& Language, 47, 469-497.

Gallo, D. A., Roediger, H. L., III, \& McDermott, K. B. (2001). Associative false recognition occurs without strategic criterion shifts. Psychonomic Bulletin \& Review, 8, 579-586.

Glisky, E. L., Rubin, S. R. \& DAvidson, P. S. R. (2001). Source memory in older adults: An encoding or retrieval problem? Journal of Experimental Psychology: Learning, Memory, \& Cognition, 27, 1131-1146.

Hicks, J. L., \& HANCOCK, T. W. (2002). Backward associative strength determines source attributions given to false memories. Psychonomic Bulletin \& Review, 9, 807-815.

Hicks, J. L., \& Marsh, R. L. (1999). Attempts to reduce the incidence of false recall with source monitoring. Journal of Experimental Psychology: Learning, Memory, \& Cognition, 25, 1195-1209.

Intons-Peterson, M. J., Rocchi, P., West, T., McLellan, K., \& HACKNEY, A. (1999). Age, testing at preferred or nonpreferred times (testing optimality), and false memory. Journal of Experimental Psychology: Learning, Memory, \& Cognition, 25, 23-40. 
JACOBY, L. L. (1999). Ironic effects of repetition: Measuring age-related differences in memory. Journal of Experimental Psychology: Learning, Memory, \& Cognition, 25, 3-22.

JACoby, L. L., Kelley, C. M., \& Dywan, J. (1989). Memory attributions. In H. L. Roediger III \& F. I. M. Craik (Eds.), Varieties of memory and consciousness: Essays in honour of Endel Tulving (pp. 391422). Hillsdale, NJ: Erlbaum.

Johnson, M. K., Foley, M. A., Suengas, A. G., \& Raye, C. L. (1988). Phenomenal characteristics of memories for perceived and imagined autobiographical events. Journal of Experimental Psychology: General, 117, 371-376.

Kensinger, E. A., \& Schacter, D. L. (1999). When true memories suppress false memories: Effects of aging. Cognitive Neuropsychology, 16, 399-415.

KoutstaAl, W., \& Schacter, D. L. (1997). Gist-based false recognition of pictures in older and younger adults. Journal of Memory \& Language, 37, 555-583.

Lampinen, J. M., Neuschatz, J. S., \& Payne, D. G. (1998). Memory illusions and consciousness: Examining the phenomenology of true and false memories. Current Psychology: Developmental, Learning, Personality, Social, 16, 181-224.

Lampinen, J. M., Neuschatz, J. S., \& Payne, D. G. (1999). Source attributions and false memories: A test of the demand characteristics account. Psychonomic Bulletin \& Review, 6, 130-135.

Leboe, J. P., \& Whittlesea, B. W. A. (2002). The inferential basis of familiarity and recall: Evidence for a common underlying process. Journal of Memory \& Language, 46, 804-829.

LindSAY, D. S., \& Kelley, C. M. (1996). Creating illusions of familiarity in a cued recall remember/know paradigm. Journal of Memory \& Langauge, 35, 197-211.

Mather, M., Henkel, L. A., \& Johnson, M. K. (1997). Evaluating characteristics of false memories: Remember/know judgments and memory characteristics questionnaire compared. Memory \& Cognition, 25, 826-837.

McKone, E., \& Murphy, B. (2000). Implicit false memory: Effects of modality and multiple study presentations on long-lived semantic priming. Journal of Memory \& Language, 43, 89-109.

Neuschatz, J. S., Payne, D. G., Lampinen, J. M., \& Toglia, M. P. (2001). Assessing the effectiveness of warnings and the phenomenological characteristics of false memories. Memory, 9, 53-71.

Norman, K. A., \& Schacter, D. L. (1997). False recognition in younger and older adults: Exploring the characteristics of illusory memories. Memory \& Cognition, 25, 838-848.

Payne, D. G., Elie, C. J., Blackwell, J. M., \& Neuschatz, J. S. (1996). Memory illusions: Recalling, recognizing, and recollecting events that never occurred. Journal of Memory \& Language, 35, 261 285.

READ, J. D. (1996). From a passing thought to a false memory in 2 minutes: Confusing real and illusory events. Psychonomic Bulletin \& Review, 3, 105-111.

Reyna, V. H., \& Tiтcomb, A. (1996). The constraints on the suggestibility of eyewitness testimony: A fuzzy trace theory analysis. In D. G. Payne \& F. C. Conrad (Eds.), Intersections in basic and applied research (pp. 27-55). Hillsdale, NJ: Erlbaum.

Robinson, K. J., \& Roediger, H. L., III (1997). Associative processes in false recall and false recognition. Psychological Science, 8, 231-237.

Roediger, H. L., III, \& McDermott, K. B. (1995). Creating false memories: Remembering words not presented in lists. Journal of Experimental Psychology: Learning, Memory, \& Cognition, 21, 803-814.

Roediger, H. L., III, McDermott, K. B., Pisoni, D. B., \& Gallo, D. A. (in press). Illusory recollection of voices. Memory.

Roediger, H. L., III, Watson, J. M., McDermott, K. B., \& Gallo, D. A. (2001). Factors that determine false recall: A multiple regression analysis. Psychonomic Bulletin \& Review, 8, 385-407.

Schacter, D. L., Israel, L., \& Racine, C. (1999). Suppressing false recognition in younger and older adults: The distinctiveness heuristic. Journal of Memory \& Language, 40, 1-24.

Schacter, D. L., Norman, K. A., \& Koutstaal, W. (1998). The cognitive neuroscience of constructive memory. Annual Review of Psychology, 49, 289-318.
Schacter, D. L., Verfaellie, M., \& Anes, M. D. (1997). Illusory memories in amnesic patients: Conceptual and perceptual false recognition. Neuropsychology, 11, 331-342.

Schacter, D. L., Verfaellie, M., \& Pradere, D. (1996). The neuropsychology of memory illusions: False recall and recognition in amnesic patients. Journal of Memory \& Language, 35, 319-334.

Seamon, J. G., Lee, I. A., Toner, S. K., Wheeler, R. H., Goodkind, M. S., \& BIRCH, A. D. (2002). Thinking of critical words during study is unnecessary for false memory in the Deese, Roediger, and McDermott procedure. Psychological Science, 13, 526-531.

Seamon, J. G., Luo, C. R., \& Gallo, D. A. (1998). Creating false memories of words with or without recognition of list items: Evidence for nonconscious processes. Psychological Science, 9, 20-26.

Seamon, J. G., Luo, C. R., Schlegel, S. E., Greene, S. E., \& GoldENBERG, A. B. (2000). False memory for categorized pictures and words: The category associates procedure for studying memory errors in children and adults. Journal of Memory \& Language, 42, 120-146.

Smith, R. E., \& Hunt, R. R. (1998). Presentation modality affects false memory. Psychonomic Bulletin \& Review, 5, 710-715.

Smith, S. M., Gerkens, D. R., Pierce, B. H., \& Choi, H. (2002). The roles of associative responses at study and semantically guided recollection at test in false memory: The Kirkpatrick and Deese hypotheses. Journal of Memory \& Language, 47, 436-447.

SNOdgrass, J. G., \& Corwin, J. (1988). Pragmatics of measuring recognition memory: Applications to dementia and amnesia. Journal of Experimental Psychology: General, 117, 34-50.

Stadler, M. A., Roediger, H. L., III, \& McDermott, K. B. (1999). Norms for word lists that create false memories. Memory \& Cognition, 27, 494-500.

Tulving, E. (1985). Memory and consciousness. Canadian Psychologist, 26, 1-12.

Tun, P. A., Wingfield, A., Rosen, M. J., \& Blanchard, L. (1998). Response latencies for false memories: Gist-based processes in normal aging. Psychology \& Aging, 13, 230-241.

Watson, J. M., Balota, D. A., \& Roediger, H. L., III (2003). Creating false memories with hybrid lists of semantic and phonological associates: Over-additive false memories produced by converging associative networks. Journal of Memory \& Language, 49, 95-118.

Whitt lesea, B. W. A. (2002). False memory and the discrepancyattribution hypothesis: The prototype-familiarity illusion. Journal of Experimental Psychology: General, 131, 96-115.

\section{NOTES}

1. As an alternative to the subtraction technique, we also adjusted hits and false alarms to related lures by using $d^{\prime}$ (which tends to be less sensitive than subtraction; see Snodgrass \& Corwin, 1988) and conducted a parallel set of analyses on the old/new data. An identical pattern of statistical results was obtained with the $d^{\prime}$ scores, the only exception being that the main effect of study modality on related lures was not significant $(F=3.47, p=.07)$. In general, the modality effects were smaller in this experiment (about $5 \%$ overall) than have been reported (see Gallo, McDermott, et al., 2001, for discussion). Given that the overall effect of modality was only marginal with $d^{\prime}$, and given that this experiment was designed to look at length effects on subjective judgments, the modality effects reported here for older adults should only be considered preliminary.

2. A reviewer noted that, because we used visual presentation at test, one might have expected more visual than auditory source judgments for related lures. We found no evidence for such a bias, indicating that the source of the corresponding study list was much more relevant to these judgments. Similarly, in work more directly aimed at understanding study/ test source matches (with voices), we found that the source of the study list influenced illusory source judgments much more than the test source did (Roediger, McDermott, Pisoni, \& Gallo, in press).

(Manuscript received January 21, 2003; revision accepted for publication May 30, 2003.) 